\title{
Las pinturas esquemáticas de la cueva de la Victoria (Rincón de la Victoria, Málaga): propuesta interpretativa del friso $\mathrm{A}$
}

\section{The schematic paintings of the cave of La Victoria (Rincón de la Victoria, Málaga): Interpretative proposal of the frieze $A$}

\author{
Rafael Maura Mijares* \\ Pedro Cantalejo Duarte** \\ M. ${ }^{a}$ deL MAR ESPEJo HeRRERÍAs ${ }^{* *}$
}

\begin{abstract}
RESUMEN
ABSTRACT

Se recoge en este artículo nuestra reciente revisión del conjunto pictórico postpaleolítico de la cueva de la Victoria. A partir de una documentación exhaustiva de los motivos representados y del análisis de su iconografía se proponen

In this article we gather the recent revision of the postpalaeolithic pictorial collection in the cave of la Victoria. Starting from an exhaustive documentation of the motifs and the analysis of its iconography, we propose some interpretative hypothesis.
\end{abstract} hipótesis de carácter interpretativo.

\section{PALABRAS CLAVE}

Arte esquemático, cueva, depósito funerario, trasfondo sociocultural.

\section{KEY WORDS}

Schematic art, cave, funeral site, sociocultural background.

\section{INTRODUCCIÓN}

Las cuevas de Rincón de la Victoria, es decir, las del Higuerón-Suizo y Victoria (hoy conocidas turísticamente como cuevas del Tesoro), se localizan en un gran

* Departamento de Prehistoria y Arqueología, UNED.

** Museo de Ardales. 
macizo de rocas sedimentarias emergidas durante el Jurásico, conocido popularmente como El Cantal. Este promontorio calizo ha sido afectado profusamente por la disolución química del agua, en un proceso de karstificación muy dinámico que ha generado infinidad de grietas en el exokarst y numerosas cavidades en el endokarst, algo que puede apreciarse en toda su magnitud en la proximidad del acantilado marino actual, dado que el resto del espacio ha sido literalmente urbanizado y dificulta la comprensión de la litología externa.

Estas grutas se abren en la parte superior del karst, conformando un complejo subterráneo de gran amplitud al que se accede por numerosos pozos verticales que conectan el exterior con diversas galerías dispuestas en el sentido de las diaclasas internas. Con un recorrido espeleológico cercano a los dos kilómetros, la geología de las cuevas del Cantal tiene un notable interés científico, tanto por su morfología de disolución, como por los diferentes períodos de desmantelamiento de espeleotemas que las cavidades han sufrido a lo largo de su historia geológica a causa de diferentes exposiciones a la erosión marina (Durán, 1994).

La cueva de la Victoria, que es la que ahora nos ocupa, es una cavidad natural de medianas proporciones (no excede los cien metros de recorrido principal), separada espeleológicamente del resto. Posee dos pozos de entrada, uno de los cuales es el de mayor amplitud del complejo, una torca que en la actualidad está debidamente protegida por una obra de fábrica y unos portones que caen a plomo en el abismo interior, al que se accede mediante una escalera de aluminio desplegada hasta el suelo de la primera sala de la cavidad, cerca del lugar donde Fortea Pérez realizó excavaciones en los años setenta. Desde este punto de partida se observa un nivel de colmatación en torno a la torca, de cuyas verdaderas dimensiones dará cuenta el futuro de la investigación. Una galería que estuvo casi colmatada al final de la Prehistoria nos lleva a unos resaltes que tendrán que salvarse por medio de tramos de escaleras también de aluminio. Al final de estas galerías estrechas y pequeñas salitas, se desemboca en una sala amplia, perpendicular a la trayectoria del resto de la cavidad. Estaríamos entonces en la conocida como sala del Dosel y, desde ella, podemos salir por el pequeño pozo que se encuentra a su izquierda.

Como hemos dicho, las excavaciones de Fortea se llevaron a cabo en la zona de penumbra de la galería principal, lugar conocido como sala de las Conchas que se sitúa bajo el gran pozo (Fortea, 1973). En esta intervención y bajo el nivel superficial que estaba ocupado por material arqueológico relacionado con el Neolíti$\mathrm{co}$, encontró un claro nivel epipaleolítico, definido por la presencia de microlitos laminares. Por último, Fortea excava un nivel paleolítico que, a tenor de algunos de sus hallazgos, sobre todo dos arpones que han sido revisados por Miguel Cortés (Cortés, 2002), se adscribe a momentos Magdalenienses.

En la misma cueva de la Victoria, mucho antes, en 1940, fueron realizadas excavaciones en la sala del Dosel, junto al pozo pequeño, a cargo de Giménez Reyna y Carlos Rein (Giménez, 1941, 1946), mediante las que fueron definidos 
tres estratos que describieron como un primer nivel superficial de casi $50 \mathrm{~cm}$ de espesor, compuesto fundamentalmente por materiales Neolíticos (vasos de cerámica, muchos de ellos con decoración, brazaletes de caliza grabados con líneas paralelas, conchas perforadas, un colmillo de jabalí con perforaciones...), un segundo nivel de unos $20 \mathrm{~cm}$ que describen como estéril, con cenizas y, por ultimo, un nivel inferior de unos $70 \mathrm{~cm}$, acerámico, con presencia de cantos rodados, sílex, gran cantidad de malacofauna y hogares.

Así pues, y con todas las reservas que impiden comparar una excavación con la otra, parece que ambas coinciden en constatar en los niveles más superficiales la presencia de vasos cerámicos, algunos claramente atribuibles al Neolítico, junto con pulseras, punzones, etc; un estrato intermedio que Fortea define como Epipaleolítico; y por fin, en la base de la secuencia, un nivel del Paleolítico superior.

Una vez descubierta la cueva de la Victoria para el mundo científico como yacimiento prehistórico, se tardó algún tiempo en constatar la existencia de pinturas rupestres. Esto es debido a que el tono que presentan estas grafías, un ocre amarillento, dificulta enormemente su apreciación, al confundirse con las concreciones del soporte calizo de la cueva. Su hallazgo se debió a las investigaciones de Martínez Santa-Olalla, según reconoce el propio Giménez Reyna en una conferencia celebrada en Málaga el 26 de Marzo de 1943 (Rubio, 1976: 235). A partir de entonces, se cuenta con la reseña efectuada por Pérez de Barradas (Pérez de Barradas, 1968), las reproducciones parciales publicadas por Muñoz Gambero (Muñoz, 1971-73) y, sobre todo, el artículo de Rubio Díaz (Rubio, 1976), a quien debemos la primera aproximación seria a este conjunto de arte esquemático.

En este breve aunque denso artículo, Rubio descarta alguna de las figuras recogidas por Muñoz Gambero y añade cinco motivos que no aparecían en las reproducciones de éste (Rubio, 1976: 236), todos ellos en la pared meridional de la sala del Dosel. También distingue siete categorías tipológicas, cuatro de ellas antropomorfas: ancoriforme, brazos en asa, extremidades superiores e inferiores indicadas y representación naturalista. Ésta última, que incluso llega a paralelizarse con fases recientes del arte levantino, tiene a nuestro juicio pocos visos de verosimilitud. Las otras tipologías consistirían en posibles armas y dos variantes de motivos de tendencia cuadrangular (Rubio, 1976: 236 y s.s.). Para este autor, cuyas reproducciones han sido hasta ahora las más difundidas, «...todo el conjunto representado se encuentra relacionado con los enterramientos del período final de utilización de la cueva» (Rubio, 1976: 242).

Ya en los años ochenta, se produce la aportación de Ana Morales y José Enrique Márquez, quienes, junto a otras estaciones con arte esquemático, relacionan también estas pinturas con su contexto arqueológico (Morales y Márquez, 1984: 186-187) y hacen extensiva su vinculación con los ritos funerarios a los enterramientos localizados en la vecina cueva del Higuerón y en la de Hoyo de la Mina (Morales y Márquez, 1984: 192). 
Con posterioridad, las pinturas de la cueva de la Victoria han sido traídas a colación en algunas publicaciones de carácter general (Santana, 2001; Maura, 2003 a) y, más recientemente, fueron objeto de una revisión por parte de Ana M. ${ }^{a}$ Márquez y José Luis Sanchidrián, labor que se realizó en el marco de los trabajos de acondicionamiento de la cavidad dirigidos por Francisco Ortiz. Sus resultados fueron incluidos en una visión de conjunto en relación con el arte esquemático en cuevas (Márquez y Sanchidrián, 2005), en el que se recoge por primera vez la existencia de otro friso localizado en el lateral contrario de la sala, ampliando el cómputo de motivos, en principio, a 116 (Márquez y Sanchidrián, 2005: 318), aunque más tarde se aclara que 18 de ellos se consideraron paleolíticos (Márquez y Sanchidrián, 2006: 419).

\section{CATÁLOGO Y DOCUMENTACIÓN GRÁFICA}

Por nuestra parte, la revisión y puesta al día de que ha sido objeto este conjunto pictórico, partiendo de una base documental preexistente (Espejo, Espinar y Cantalejo, 1986; Espejo y Cantalejo, 1996), ha seguido un proceso metodológico análogo al desarrollado para el arte paleolítico registrado en este mismo complejo (Cantalejo et al. 2007; Espejo et al., 2007), así como en otros enclaves de arte prehistórico de la provincia de Málaga (Maura y Cantalejo, 2004; Cantelejo et al., 2006; Cantalejo, Maura y Becerra, 2006)

Como se ha indicado, las manifestaciones rupestres postpaleolíticas de las cuevas del Cantal se concentran en las galerías independientes que constituyen la cueva de la Victoria, y más concretamente en una de sus estancias, la conocida como sala del Dosel, sin que se haya localizado vestigio alguno susceptible de ser adscrito a esta etapa en otros sectores de este complejo subterráneo.

El arte esquemático de la cueva de la Victoria queda dividido en dos grandes frisos enfrentados de forma simétrica en relación con el eje longitudinal de la sala, obteniéndose una especie de disposición en espejo, aunque las figuras de una pared no encuentran su reflejo en la otra. Además, la longitud aparente de los espacios pintados en ambas viene a ser casi la misma, si bien se trata de un efecto óptico, ya que el friso meridional mide $6,35 \mathrm{~m}$ de largo mientras que el otro tiene sólo 4,55 m.

Con el fin de ordenar la clasificación, hemos designado con la sigla $A$ al friso reconocido tradicionalmente, es decir, a la derecha en el sentido de la penetración desde la entrada natural más próxima (pozo chico), y con la sigla B al que se localiza en el lateral izquierdo. En el siguiente cómputo general se recogen los vestigios de ambos frisos, cada uno de los cuales fue dividido a su vez en doce paneles, ascendiendo la cifra total de motivos a 121 elementos, 89 pertenecientes al friso $A$ y 32 al friso $B$ : 


\begin{tabular}{|l|c|c|c|c|c|c|c|c|c|c|c|c|c|}
\cline { 2 - 15 } \multicolumn{1}{c|}{} & \multicolumn{10}{c|}{ PANELES } & \multicolumn{1}{c|}{} \\
\cline { 2 - 14 } & I & II & III & IV & V & VI & VII & VIII & IX & X & XI & XII & Totales \\
\hline Friso A & 3 & 4 & 6 & 2 & 4 & 7 & 17 & 8 & 9 & 10 & 14 & 5 & 89 \\
\hline Friso B & 2 & 1 & 1 & 1 & 9 & 1 & 2 & 5 & 4 & 3 & 1 & 2 & 32 \\
\hline
\end{tabular}

Existe, como vemos, una notable descompensación en cuanto al número de motivos representados en uno y otro friso a favor del primero, lo que debe explicarse en función del mayor grado de deterioro que presenta el friso $B$, cubierto de concreciones y excrecencias, como ocurre en el A, a lo que hay que sumar el haber estado sometido a lavados mucho más intensos, cuya actividad ha generado una película de carbonato cálcico que se superpone a muchas figuras. También deben buscarse en estas circunstancias las razones por las que los vestigios de esta pared no fueran localizados o tenidos en cuenta hasta estos últimos años.

Según el sistema que hemos seguido para la siguiente clasificación, los paneles, y en la medida de lo posible las figuras, quedan ordenados en el sentido de la penetración, es decir, de derecha a izquierda en el friso $A$ y de izquierda a derecha en el B. Para las referencias tipológicas hemos procurado ceñirnos a la terminología clásica representada por el trinomio Breuil-Acosta-Bécares.

\begin{tabular}{|c|c|c|}
\hline & & Friso A \\
\hline PANEL & MOTIVO & TIPOLOGÍA \\
\hline \multirow{3}{*}{ I } & 1 & Antropomorfo ancoriforme (incompleto). \\
\hline & 2 & Indefinido. \\
\hline & 3 & Indefinido. \\
\hline \multirow{4}{*}{ II } & 1 & Antropomorfo con piernas y brazos en arco y sexo indicado. \\
\hline & 2 & Antropomorfo ancoriforme. \\
\hline & 3 & Signo complejo. \\
\hline & 4 & Signo en ángulo. \\
\hline \multirow{6}{*}{ III } & 1 & Antropomorfo ancoriforme. \\
\hline & 2 & Indefinido. \\
\hline & 3 & Antropomorfo ancoriforme. \\
\hline & 4 & Indefinido. \\
\hline & 5 & Indefinido. \\
\hline & 6 & Antropomorfo ancoriforme (incompleto). \\
\hline
\end{tabular}


(Continuación)

\begin{tabular}{|c|c|c|}
\hline \multirow{2}{*}{ IV } & 1 & Signo en corchete. \\
\hline & 2 & Indefinido. \\
\hline \multirow{4}{*}{$\mathrm{V}$} & 1 & Antropomorfo ancoriforme. \\
\hline & 2 & Antropomorfo ancoriforme. \\
\hline & 3 & Signo en barra vertical. \\
\hline & 4 & Indefinido. \\
\hline \multirow{7}{*}{ VI } & 1 & Indefinido. \\
\hline & 2 & Signo en cuatro barras verticales. \\
\hline & 3 & Antropomorfo ancoriforme. \\
\hline & 4 & Antropomorfo de «brazos en asa». \\
\hline & 5 & Indefinido. \\
\hline & 6 & Antropomorfo ancoriforme. \\
\hline & 7 & Antropomorfo ancoriforme (incompleto). \\
\hline \multirow{17}{*}{ VII } & 1 & Antropomorfo ancoriforme. \\
\hline & 2 & Antropomorfo ancoriforme. \\
\hline & 3 & Indefinido. \\
\hline & 4 & Signo en barra horizontal. \\
\hline & 5 & Antropomorfo «tipo golondrina». \\
\hline & 6 & Antropomorfo ancoriforme. \\
\hline & 7 & Signo en ángulo. \\
\hline & 8 & Indefinido. \\
\hline & 9 & Antropomorfo ancoriforme. \\
\hline & 10 & Signo en ángulo. \\
\hline & 11 & Antropomorfo ancoriforme. \\
\hline & 12 & Antropomorfo ancoriforme (incompleto). \\
\hline & 13 & Antropomorfo ancoriforme. \\
\hline & 14 & Signo en dos barras verticales. \\
\hline & 15 & Antropomorfo ancoriforme (incompleto). \\
\hline & 16 & Antropomorfo ancoriforme. \\
\hline & 17 & Antropomorfo ancoriforme. \\
\hline
\end{tabular}

(Continúa) 
Las pinturas esquemáticas de la cueva de la Victoria (Rincón de la Victoria, Málaga)...

(Continuación)

\begin{tabular}{|c|c|c|}
\hline \multirow{8}{*}{ VIII } & 1 & Signo en ángulo. \\
\hline & 2 & Signo en barra vertical. \\
\hline & 3 & Indefinido. \\
\hline & 4 & Antropomorfo ancoriforme. \\
\hline & 5 & Indefinido. \\
\hline & 6 & Antropomorfo ancoriforme. \\
\hline & 7 & Indefinido. \\
\hline & 8 & Signo en barra oblicua. \\
\hline \multirow{9}{*}{ IX } & 1 & Antropomorfo en doble «T». \\
\hline & 2 & Signo en ángulo. \\
\hline & 3 & Indefinido. \\
\hline & 4 & Antropomorfo cruciforme armado con piernas en arco. \\
\hline & 5 & Signo cuadrangular con barra vertical interior. \\
\hline & 6 & Antropomorfo ancoriforme asociado a dos barras horizontales. \\
\hline & 7 & Signo cuadrangular con barra vertical interior. \\
\hline & 8 & Antropomorfo ancoriforme. \\
\hline & 9 & Antropomorfo ancoriforme. \\
\hline \multirow{10}{*}{$x$} & 1 & Indefinido. \\
\hline & 2 & Antropomorfo ancoriforme. \\
\hline & 3 & Antropomorfo ancoriforme. \\
\hline & 4 & Antropomorfo ancoriforme. \\
\hline & 5 & Antropomorfo ancoriforme. \\
\hline & 6 & Indefinido. \\
\hline & 7 & Antropomorfo ancoriforme. \\
\hline & 8 & Antropomorfo ancoriforme. \\
\hline & 9 & Antropomorfo ancoriforme (incompleto). \\
\hline & 10 & Antropomorfo ancoriforme. \\
\hline
\end{tabular}

(Continúa) 
(Continuación)

\begin{tabular}{|c|c|c|}
\hline \multirow{14}{*}{$\mathrm{XI}$} & 1 & Antropomorfo ancoriforme. \\
\hline & 2 & Antropomorfo ancoriforme. \\
\hline & 3 & Antropomorfo ancoriforme. \\
\hline & 4 & Antropomorfo ancoriforme. \\
\hline & 5 & Antropomorfo ancoriforme. \\
\hline & 6 & Antropomorfo ancoriforme. \\
\hline & 7 & Antropomorfo ancoriforme. \\
\hline & 8 & Antropomorfo ancoriforme. \\
\hline & 9 & Antropomorfo ancoriforme. \\
\hline & 10 & Antropomorfo ancoriforme (incompleto). \\
\hline & 11 & Antropomorfo ancoriforme. \\
\hline & 12 & Antropomorfo ancoriforme. \\
\hline & 13 & Antropomorfo ancoriforme (incompleto). \\
\hline & 14 & Antropomorfo ancoriforme. \\
\hline \multirow{5}{*}{ XII } & 1 & Signo en barra vertical. \\
\hline & 2 & Indefinido. \\
\hline & 3 & Antropomorfo ancoriforme. \\
\hline & 4 & Indefinido. \\
\hline & 5 & Antropomorfo ancoriforme. \\
\hline \multicolumn{3}{|r|}{ Friso B } \\
\hline PANEL & MOTIVO & TIPOLOGÍA \\
\hline \multirow{2}{*}{ I } & 1 & Antropomorfo ancoriforme (incompleto). \\
\hline & 2 & Signo en barra vertical. \\
\hline II & 1 & Signo complejo. \\
\hline III & 1 & Antropomorfo ancoriforme. \\
\hline IV & 1 & Indefinido. \\
\hline
\end{tabular}

(Continúa) 
(Continuación)

\begin{tabular}{|c|c|c|}
\hline \multirow{9}{*}{$\mathrm{V}$} & 1 & Indefinido. \\
\hline & 2 & Indefinido. \\
\hline & 3 & Antropomorfo ancoriforme (incompleto). \\
\hline & 4 & Indefinido. \\
\hline & 5 & Signo en barra oblicua. \\
\hline & 6 & Antropomorfo ancoriforme (incompleto). \\
\hline & 7 & Signo en barra vertical. \\
\hline & 8 & Indefinido. \\
\hline & 9 & Antropomorfo ancoriforme. \\
\hline VI & 1 & Antropomorfo ancoriforme. \\
\hline \multirow{2}{*}{ VII } & 1 & Signo en barra vertical. \\
\hline & 2 & Antropomorfo ancoriforme. \\
\hline \multirow{5}{*}{ VIII } & 1 & Antropomorfo ancoriforme. \\
\hline & 2 & Antropomorfo ancoriforme (incompleto). \\
\hline & 3 & Indefinido. \\
\hline & 4 & Indefinido. \\
\hline & 5 & Indefinido. \\
\hline \multirow{4}{*}{ IX } & 1 & Antropomorfo ancoriforme. \\
\hline & 2 & Signo en barra vertical. \\
\hline & 3 & Indefinido. \\
\hline & 4 & Indefinido. \\
\hline \multirow{3}{*}{$X$} & 1 & Antropomorfo ancoriforme. \\
\hline & 2 & Indefinido. \\
\hline & 3 & Indefinido. \\
\hline $\mathrm{XI}$ & 1 & Antropomorfo ancoriforme. \\
\hline \multirow{2}{*}{ XII } & 1 & Antropomorfo ancoriforme (incompleto). \\
\hline & 2 & Signo cuadrangular (incompleto). \\
\hline
\end{tabular}

\section{TÉCNICAS DE EJECUCIÓN}

Sin duda, la variante técnica más llamativa y peculiar de este conjunto de motivos esquemáticos es la tonalidad que presentan, con escasos paralelos conocidos. Se trata de un color que originalmente debió ser casi blanco, aunque en la actualidad ha virado fuertemente hacia el amarillo, llegando en algunas ocasiones a adquirir tonos grisáceos y hasta verdosos. Se empleó una solución relativa- 
mente espesa, probablemente de base calcárea, que debió aplicarse con los dedos, ya que así parecen indicarlo los anchos de los trazos, muy regulares y en torno al centímetro, así como el hecho de que en ningún caso sean superiores a los diez-doce centímetros, que es la longitud máxima que permite la capacidad de carga de un dedo humano. La textura actual de estas aplicaciones registra un estado de conservación dispar, muy absorbida por el soporte en algunos casos, mientras que en otros se advierten descamaciones o lavados producto de la actividad litoquímica. A veces, incluso, lo que nos ha quedado no pasa de ser una tenue impronta sin pigmento alguno. Todas estas alteraciones han contribuido a sembrar de dificultades nuestras apreciaciones tipológicas, además de suponer serios contratiempos a la hora de abordar los trabajos de calcografía.

La apariencia general es muy homogénea, tanto entre motivos como entre ambos frisos, lo que podría indicar que estamos ante un conjunto de marcado carácter sincrónico. Como única excepción contamos con el motivo B. XI. 1, cuyo cromatismo lo separa radicalmente del resto de esquemas. Este elemento presenta una tonalidad muy oscurecida, de apariencia casi negra, aunque las imágenes macroscópicas han revelado un sustrato rojizo que parece remitirnos a su color original. A pesar de dicha anomalía, decidimos incluir dicho motivo en el conjunto esquemático de esta cueva, debido, sobre todo, a que comparte tipología, medidas y proporciones con otras figuras antropomorfas registradas en este mismo conjunto. Debe señalarse también que se trata de un motivo extremadamente afectado por la actividad litoqímica, que lo ha cubierto de una densa capa de carbonato cálcico.

Como norma, se prefieren las superficies más favorables y los grupos de figuras tienden a adaptarse a los espacios naturales creados por el modelado kárstico, como concavidades, convexidades y espeleotemas. En este sentido destacaríamos el panel A. II, realizado sobre una gruesa estalactita, y el panel B. X, donde cada motivo se dispone consecutivamente en el interior de una pequeña hornacina.

\section{TEMÁTICA Y TIPOLOGÍA}

Como se ha comentado más arriba, el grado de deterioro del panel $B$ es mucho más acentuado que el del $A$, aunque éste no deja de presentar un estado de conservación lamentable, cuyo progresivo desgaste ha continuado hasta fechas recientes. Esta circunstancia, además de la propia índole de los esquemas que estudiamos, sustancialmente conceptuales, dificulta enormemente el establecimiento de criterios temáticos y tipológicos, aunque puede concluirse que los temas representados son fundamentalmente antropomorfos y signos, e incluso, ciertamente, puede haberse querido representar también algún tipo de objeto, en cuyo caso han sido considerados como elementos añadidos al antropomorfo que los porta. A pesar de ello, debe reconocerse que algunas de las atribuciones que aquí presentamos son dudosas, ya que muchos motivos han llegado hasta nosotros de 
forma parcial o incompleta, limitación que, ineludiblemente, debe haber distorsionando nuestras interpretaciones.

En cuanto a los restos que no fue posible incluir en una de estas dos categorías, han quedado agrupados en el grupo impreciso de los «indefinidos». He aquí un computo de los motivos en relación con sus temáticas:

\begin{tabular}{|l|c|c|c|c|}
\hline & Antropomorfos & Signos & Indefinidos & Totales \\
\hline Friso A & 54 & 16 & 19 & $\mathbf{8 9}$ \\
\hline Friso B & 13 & 7 & 12 & $\mathbf{3 2}$ \\
\hline Totales & $\mathbf{6 7}$ & $\mathbf{2 3}$ & $\mathbf{3 1}$ & $\mathbf{1 2 1}$ \\
\hline
\end{tabular}

\subsection{Antropomorfos}

La tipología antropomorfa es la más numerosa del conjunto, con 67 individuos representados, lo que supone el $55,3 \%$ del total de los elementos compositivos, 55 de los cuales se localizaron en el friso A y 13 en el B. Destaca, sobre otras variables, el altísimo porcentaje de ancoriformes, un $91 \%$ de los antropomorfos y un $51,2 \%$ del total de motivos. Esta incidencia proporcional contrasta con la presencia casi puntual de otras tipologías como los cruciformes, «Brazos en asa», «Tipo golondrina», en doble «T» y con los brazos y las piernas en arco, lo que confiere a estas figuras un indudable sello de distinción en el propio contexto del conjunto.

\begin{tabular}{|l|c|c|c|}
\hline \multirow{2}{*}{} & \multicolumn{3}{|c|}{ ANTROPOMORFOS } \\
\cline { 2 - 4 } & Friso A & Friso B & Totales \\
\hline Ancoriforme & 49 & 13 & $\mathbf{6 2}$ \\
\hline Cruciforme con las piernas en arco & 1 & - & $\mathbf{1}$ \\
\hline «Brazos en asa» & 1 & - & $\mathbf{1}$ \\
\hline «Tipo golondrina» & 1 & - & $\mathbf{1}$ \\
\hline En doble «T» & 1 & - & $\mathbf{1}$ \\
\hline Brazos y piernas en arco & 1 & - & $\mathbf{1}$ \\
\hline Totales & $\mathbf{5 5}$ & $\mathbf{1 3}$ & $\mathbf{6 7}$ \\
\hline
\end{tabular}

La mayoría de estas figuras humanas se basan en un esquema simple que representa el tronco y las extremidades superiores. En este orden se incluyen los antropomorfos de «Brazos en asa», «Tipo golondrina» y, por supuesto, ancoriformes. Estos últimos presentan en la cueva de la Victoria diferentes variantes, en relación, sobre todo, al modo en que se disponen los brazos, que van desde los que forman prácticamente un ángulo, hasta los muy redondeados, pasando por aquellos que adoptan una forma acodada. 
Las extremidades inferiores aparecen expresadas únicamente en los tipos doble «T», cruciforme con las piernas en arco y antropomorfo con los brazos y las piernas en arco. Este último (A. II. 1), debido precisamente a la incorporación de las piernas, tiene un tamaño ligeramente superior al resto, lo que constituye también un rasgo diferencial añadido, siendo además el único caso en el que el sexo parece haberse querido representar de forma explícita. Esta circunstancia adquiere mayor alcance al comprobarse que los antropomorfos de estos frisos no se completan con otros detalles corporales o relativos al atuendo, aunque en ocasiones sí se presentan íntimamente yuxtapuestos a otras formas. Los casos más elocuentes los encontramos en el panel A. IX, donde aparece un antropomorfo cruciforme con las piernas en arco que aparenta portar en ambas manos algún tipo de arma (A. IX. 4). A su derecha, una figura que parece híbrida entre un ancoriforme y una doble «T» (A. IX. 6). Pero también pueden atisbarse asociaciones con signos. Las extremidades inferiores del antropomorfo armado enmarcan a un signo cuadrangular con travesaño vertical (A. IX. 7) dispuesto a sus pies, y sobre este individuo, un antropomorfo en doble «T» (A. IX. 1) se pinta junto a un signo en ángulo (A. IX.), y en su mismo plano. Esta asociación antropomorfo-ángulo adquiere su máxima expresión entre los motivos A. VII. 9 y A. VII. 10, cuyas connotaciones interpretativas, como veremos, podrían tener notable incidencia.

\subsection{Signos}

Los signos conservados, 24 motivos, suponen un 19,8 \% del total de elementos compositivos. El menor número de signos documentados en el friso $\mathrm{B}$ es acorde con la desproporción que se constata entre el número de antropomorfos presentes en ambos frisos. Los más abundantes son las barras verticales, aunque debemos ser prudentes respecto a esta valoración, porque es posible que en algunos casos se trate de restos pertenecientes a motivos más complejos. Esta cautela debe hacerse extensiva al resto de signos en barras. También los ángulos adquieren un alto valor porcentual, y su adscripción tipológica es en general más fiable. Estos signos parecen exclusivos del friso $A$, aunque, como venimos diciendo, el estado parcial en que estas pinturas nos han llegado nos impide ser categóricos respecto a estos extremos. Otro signo varias veces repetido es el rectangular, casi siempre dividido por un travesaño vertical. Aquí han sido considerados como signos, si bien otros autores los hubieran valorado como elementos de carácter antropomorfo. Muy complejo es el caso del corchete, cuya presencia es testimonial y que, como ocurre con las barras, puede tratarse del vestigio residual de una figura perdida. Y aún más lo es el del motivo B. II. 1, formado por trazos que se revuelven y entrecruzan, cuya tipificación no acertamos a atisbar. Por último, en esta misma categoría de signos complejos, hemos incluido un esquema singular (A. II. 3), descrito correctamente por Rubio como una forma poligonal abierta en su parte inferior dentro del cual «aparece inscrita una representación arborescente o ramiforme» (Rubio, 1976: 239). En un sentido amplio, 
Las pinturas esquemáticas de la cueva de la Victoria (Rincón de la Victoria, Málaga)...

\begin{tabular}{|l|c|c|c|}
\hline & \multicolumn{3}{|c|}{ SIGNOS } \\
\cline { 2 - 4 } & Friso A & Friso B & Totales \\
\hline Barra vertical & 3 & 4 & $\mathbf{7}$ \\
\hline Ángulo & 5 & - & $\mathbf{5}$ \\
\hline Rectangular & 3 & 1 & $\mathbf{4}$ \\
\hline Barra oblicua & 1 & 1 & $\mathbf{2}$ \\
\hline Barra horizontal & 1 & - & $\mathbf{1}$ \\
\hline Dos barras verticales & 1 & - & $\mathbf{1}$ \\
\hline Cuatro barras verticales & 1 & - & $\mathbf{1}$ \\
\hline Corchete & 1 & - & $\mathbf{2}$ \\
\hline Signo complejo & 1 & 1 & $\mathbf{2 4}$ \\
\hline Totales & $\mathbf{1 7}$ & $\mathbf{7}$ & \\
\hline
\end{tabular}

cabría su clasificación entre los «ídolos estela», aunque también podría tratarse simplemente de un signo compuesto, dado que ambas son categorías tipológicas definidas.

\section{RASGOS ESTILÍSTICOS Y CRONOLOGÍA}

Como venimos observando, los motivos incluidos en este conjunto presentan un estilo basado en formas abreviadas y reducidas a los rasgos más esenciales, lo que viene a confirmar su valoración en el seno del arte esquemático típico, entroncando sin mayores dificultades con el fenómeno esquemático en general y con el registrado en la zona malagueña en particular, donde pueden encontrarse multitud de paralelos gráficos encasillables en la misma corriente artística (Maura, 2003 a).

La cronología de amplio espectro estimada para el arte esquemático en la provincia de Málaga se mueve entre un Neolítico medio-final y, tal vez, un Bronce inicial. Dado que, hoy por hoy, la ciencia no cuenta con procedimientos capaces de obtener una datación directa de pigmentos - a excepción de los negros, cuyo único referente son los muestreos realizados en la Cueva de la Pileta que ofrecieron fechas en torno a un Calcolítico final (Sanchidrián y Márquez, 2003)-, y teniendo siempre en el punto de mira ajustar una aproximación cronológica a las pinturas de la cueva de la Victoria, nuestras apreciaciones sólo pueden basarse en métodos indirectos, comenzando por analizar la secuencia crono-cultural que nos ofrecen los enclaves artísticos que cuentan además con registros arqueológicos asociados.

La primera correlación a considerar sería la de esta misma cueva, prestando especial atención a los restos excavados en la sala del Dosel que alberga las pinturas. Las prospecciones practicadas en ella (Giménez Reyna, 1941, 1946) ofre- 
cieron, como se ha dicho, tres niveles estatigráficos. En el superior, de entre $30 \mathrm{y}$ $50 \mathrm{~cm}$ de espesor, se encontraron numerosos restos óseos junto a vasos cerámicos, hachas pulimentadas y objetos de adorno, adscritos sensu lato hacia un $\mathrm{Ne}-$ olítico final-Calcolítico (Navarrete, 1976). El estrato intermedio, de $20 \mathrm{~cm}$ apareció estéril, mientras que el más profundo correspondería a momentos epipaleolíticos y magdalenienses, con restos de hogares, sílex, cantos y conchas. Como es lógico, dadas las características de las manifestaciones gráficas que tratamos, estas deben relacionarse con el nivel más superficial, cuyo cariz es marcadamente funerario y ritual.

En la provincia de Málaga y, en general, por toda Andalucía Central, es donde la connivencia entre arte esquemático y enterramientos en recintos subterráneos se hace más patente (Márquez y Sanchidrián, 2005). Debe destacarse que en las cinco cuevas malagueñas que, para nosotros, contienen con seguridad arte esquemático, es decir, Nerja, La Victoria, Sima de la Curra, Gato y Pileta, se han hallado también enterramientos humanos prehistóricos, cuya cronología se estima en todos los casos en torno a un horizonte Neolítico reciente-Calcolítico.

En definitiva, el registro arqueológico con el que están relacionadas las manifestaciones rupestres esquemáticas malagueñas nos remite insistentemente a una banda cronológica que comienza el final del Neolítico y que perdura a lo largo de todo el Calcolítico. Pero, como decimos, este espectro cronológico es quizá poco preciso. Y creemos que, como intentaremos defender, para este conjunto de la cueva de la Victoria cabría una aproximación más ajustada, utilizando como argumento de reflexión el análisis formal y conceptual de las propias manifestaciones artísticas.

\section{ESTUDIO ICONOGRÁFICO DEL FRISO A}

El friso A de la cueva de la Victoria, tanto por el nutrido número de elementos que lo componen como por su ordenamiento y disposición, constituye un objeto de estudio excepcional a la hora de permitir abordar propuestas de carácter interpretativo. La nuestra se formula a partir del análisis de la estructura gráfica de la composición y de los posibles recursos expresivos referentes a cuestiones como el género y el rango social de los individuos caracterizados, los objetos con que se asocian o los lugares en que aparecerían representados.

Como norma general, los grupos de figuras se disponen consecutivamente a lo largo de ambas paredes, conformando cada friso, en principio, una composición de desarrollo horizontal. Sin embargo, observando el ordenamiento de algunos grupos se detecta también cierta tendencia a la verticalidad, muy acusada en ciertos paneles del friso $\mathrm{A}(\mathrm{VI}, \mathrm{IX}$ y $\mathrm{XI})$. Además, en el panel $\mathrm{A}$. IX, el único antropomorfo en doble «T» de todo el conjunto (A. IX. 1) se sitúa en la parte superior, siendo a su vez el motivo emplazado a mayor altura de toda la composición, dotando también a la estructura de un interesante sesgo piramidal. 
Los paneles A. VII y A. VIII, situados exactamente sobre el hueco que da acceso al resto de galerías de la cavidad, constituirían el centro de la composición, flanqueado por el panel A. VI (arriba a la derecha) y por el A. IX (arriba a la izquierda). A partir de esta configuración medular se vertebran otros grupos de figuras a derecha e izquierda, contribuyendo así a incrementar la sensación de simetría que ya vimos respecto a la disposición enfrentada de ambos frisos. Del mismo modo, la configuración de todo el friso $A$, en torno al paso a los espacios más profundos de la cueva, nos remite también, esta vez desde una perspectiva más global, al interés por adaptarse a la naturaleza del continente que anteriormente se ha puesto de relieve en cuanto a la selección de los espacios pictóricos orientada a agrupar las figuras en función de las formas ofrecidas por el soporte.

También se observan distintas organizaciones en el seno de cada grupo. Las figuras del panel $\mathrm{A}$. VI, tienden a un orden, tampoco exento de simetrías, que se contrapone al resto de paneles, de apariencia más caótica. Sin embargo, todos ellos parecen tener en común que los motivos se articulan en torno a una figura antropomorfa significativa, bien por su tipología discordante, bien por su tamaño. Los motivos aglutinantes más nítidos serían los siguientes: A. I. 1; A. II. 1; A. III. 3; A. V. 2; A. VI. 4; A. VII. 9-10; A. IX. 4; A. XII. 3. Es interesante la disposición de las figuras en el grupo central, situado inmediatamente sobre la boca de acceso a las demás galerías, con un esquema compositivo de tendencia circular.

Finalmente, debemos destacar dos grupos cuya variedad tipológica excede la norma, el panel A. II (antropomorfo con brazos y piernas en arco-ancoriforme-signo complejo-ángulo) y el panel A. IX (antropomorfo en doble «T»-cruciforme armado-ancoriforme-ángulo-rectángulo), variabilidad que confiere a estas asociaciones un destacado valor de análisis.

Esté relacionado o no con el mundo de las creencias ultraterrenas y las prácticas de inhumación, que creemos que sí, lo cierto es que no parece que este conjunto grafico se limitara a un mero recuento de individuos. De hecho, como estamos viendo, las figuras humanas no aparecen desligadas entre sí, sino claramente concentradas en grupos, y probablemente se buscaran espacios propicios conformados por los relieves de la pared para hacerlo y no al revés, es decir, que los motivos se condensaran en determinadas zonas para adaptarse a las superficies favorables que ofrecía el soporte. Esta presunción pondría en evidencia la intención de expresar ciertas diferenciaciones dentro de la comunidad representada, mediante un convencionalismo en el que cada individuo queda relacionado con un grupo, y no con otro, en función a su pertenencia al mismo, lo que equivaldría a considerarlos, bien como miembros de una misma familia o linaje (Martínez, 198889), bien como secciones relacionadas con los modos de trabajo. Así pues, interpretada esta estructura compositiva como reflejo de una realidad social (Martínez, $2002,2006)$, las disposiciones verticales de algunos de estos grupos dentro de un esquema de desarrollo horizontal nos remitirían a un modelo de sociedad tribal de 
base colectiva, aunque de tendencia jerarquizante. El carácter eminentemente homogéneo de esta realidad social se manifestaría mediante el predominio abrumador de una tipología, la de los ancoriformes, lo que, como se ha comentado, confiere a su vez al resto de categorías tipológicas un importante carácter de diferenciación e individualización que se personifica, más que en ninguna otra, en la figura en doble «T», representada en la cúspide de la composición.

Partiendo de este planteamiento general, para representar a la gente común, el autor (quizá los autores) pudo valerse de la tipología ancoriforme, pero ciertos personajes fueron distinguidos del resto, dotándoles de rasgos diferenciales bien definidos, caso, entre otros, de la figura en doble «T», la de «brazos en asa», el individuo armado o del antropomorfo con piernas y brazos en arco con el sexo indicado. La importancia de éste último es incuestionable, ya que, como hemos venido argumentando, no sólo es el único cuyas connotaciones sexuales, en este caso masculinas, se hacen evidentes, sino que también se trata del antropomorfo de mayor altura de todo el conjunto. Además, ostenta un lugar de privilegio en el friso $\mathrm{A}$, situado al extremo de la derecha, en la zona proximal de la gruesa estalactita que le sirve de soporte, lo que la convierte en la figura más externa del conjunto, y a la altura de los ojos, siendo probablemente una de las primeras figuras que saltaría a la vista una vez se accediera al interior de la sala. La indicación del sexo masculino adquiere en este caso interesantes connotaciones, ya que en otros personajes significados por su tipología no ancoriforme, a los que, como veremos, cabría atribuir atribuciones masculinas (cruciforme armado y antropomorfo en doble «T»), no queda señalado.

Otra forma significada por su tipología es la figura de «brazos en asa» (A. VI. 4). En este motivo las extremidades superiores se cierran hasta volverse a unir en la parte inferior, conformando una morfología ovoide que queda dividida en dos por la disposición vertical del vástago central. Esta simbología podría hacer referencia a la vulva femenina, siendo quizá la única figura de todo el conjunto a la que cabría atribuir esta condición, ya que si asumimos que en los ancoriformes las extremidades superiores se quisieron expresar mediante la línea curva transversal (abierta, no cerrada como en el caso de la figura de «brazos en asa»), el vástago central constituiría en sí mismo una forma fálica, lo que nos conduciría a pensar que si el sexo de estas tipologías y en esta composición en concreto quiso significarse, algo que no queda del todo claro por ahora, éste debió ser masculino.

El signo complejo «tipo estela» ha sido definido como una figura ramiforme inscrita en una forma rectangular abierta por su parte inferior. Para Pilar Acosta, algunos ramiformes «bien podrían considerarse como la visión sintética de varias figuras humanas alineadas» (Acosta, 1983: 17). Esta propuesta parece válida para los arboriformes «simples» y "compuestos" (Bécares, 1983: 147) en los que los vástagos verticales en los que se basan las representaciones antropomorfas habrían quedado reducidas a uno común, mientras que los componentes transversales con los que se expresan las extremidades se superponen repetitivamente. En 
estos casos puede entenderse que la asimilación de una serie de figuras humanas al mismo motivo responde a que quiere significarse una relación entre ellas, de la índole que sea. En este sentido, los ramiformes «complejos» (Bécares, 1983: 147) no serían más que el desarrollo de los tipos más simples con una significación de grupos más amplios e integrados por un mayor número de elementos. El que nos ocupa, a juzgar por las fotografías que se conservan, ya que este motivo ha sufrido constantes agresiones que han ocasionado la pérdida del tercio inferior de la figura, puede calificarse sin problemas como un ramiforme típico. No es común hallarlos incluidos en otra figura, aunque sí existen algunos paralelos de este tipo de asociación.

Una interpretación libre, aunque no por ello menos legítima, de este tipo de motivos, sería la de un grupo de individuos unidos por algún tipo de vínculo y congregados en un recinto o bajo un techo. La naturaleza de este lugar podría discutirse: un habitáculo, un abrigo rocoso al aire libre... o tal vez una tumba, en este caso la propia cueva, entendiendo la figura ramiforme como un convencionalismo gráfico relativo a los seres humanos sepultados en su interior. Asumidos los riesgos de esta interpretación, la lectura del friso A adquiere una nueva dimensión, porque ya no contaríamos únicamente con figuras humanas más o menos ordenadas, algunas de ellas dotadas de cierta individualización, sino también con la representación de un lugar, en este caso el dedicado la muerte, al que se asocia la figura antropomorfa nítidamente masculina. Dándole la vuelta a este argumento, podría incluso sugerirse que si existió también un lugar antagónico y compensatorio, el dedicado a la vida, bien podría estar referenciado mediante el grupo representado en el panel $\mathrm{A}$. $\mathrm{VI}$, cuya figura principal en forma de vulva nos indicaría la condición femenina de este personaje.

Analicemos ahora el panel A. IX. Presidiendo el grupo y en la cúspide de la composición se encuentra la figura en doble «T», que es la que reúne el mayor numero de parámetros distintivos, entre los que se encuentra, por supuesto, la propia posición que ocupa en la estructura compositiva: tipología no ancoriforme, indicación de las extremidades inferiores, formato sobredimensionado y asociación con signo. Tales atributos confirmarían que podría tratarse del personaje de mayor relevancia del grupo, es decir, el situado en la cúspide de la escala jerárquica. Bajo esta figura, en un estrato inferior del escalafón, se dibuja la figura del hombre armado que adopta una actitud defensiva. Si este grupo representara también un punto en el territorio, sería aquel donde se concentra el poder, situado en un paraje elevado desde el que se controla la demarcación y sus moradores, es decir, la aldea. Las implicaciones de esta idea adquirirían gran importancia a la hora de aproximarnos aún más al momento en que este friso pudo ser pintado, ya que los patrones de asentamiento basados en poblados localizados en puntos estratégicos en altura para la defensa y control del territorio no se dan hasta el Calcolítico. Esta hipótesis ayudaría también a caracterizar el tipo de armas que porta uno de los personajes, ya que antes de ser entendido como un cazador provisto de arco y flecha, se trataría de un guerrero armado con espada o lanza y escudo, algo que en- 
caja mejor con estos episodios más avanzados en los que las sociedades incrementan decididamente su grado de belicosidad.

En el apartado en que se han analizado las tipologías, al final del párrafo dedicado a los antropomorfos, se señalaba la asociación entre un ancoriforme y un signo en ángulo. Su interpretación como un hombre que porta una herramienta resulta bastante clara, pudiendo además sugerirse que se trata de un apero de labranza, tal vez una azuela. Este mismo signo aparece repetido hasta tres veces en el grupo central de la composición, ese que se coloca sobre el dintel del acceso a las siguientes galerías, siendo además el único signo claro detectado en dicho grupo, por lo demás, el que más motivos presenta de todo el friso (25 elementos). Sería factible, por lo tanto, considerar que esta agrupación de figuras puede estar haciendo alusión a las tareas agrícolas, lo que implicaría también admitir que se estaría haciendo referencia a otro lugar: los campos de cultivo. Sin embargo, la disposición en círculo de estas figuras que ya ha sido reseñada, nos remitiría quizá a una celebración o reunión festiva, en tal caso relacionada con algún aspecto de la agricultura. Por otro lado, la asociación de una de estas «herramientas» con la figura en doble «T» a la que atribuimos la idea de jefatura, podría llevar también implícitas atribuciones relacionadas con la gestión redistributiva de los recursos económicos.

Así pues, parece factible que algunos referentes territoriales y culturales, como los espacios destinados al hábitat, al trabajo o al culto a la vida y a la muerte quedaran aquí representados, y es posible que fueran algunos más. Sin embargo, la merma de elementos de juicio causada por el paso del tiempo y las actividades erosivas naturales y antrópicas o, incluso nuestra falta de pericia y hasta de valentía a la hora de plantearnos ampliar esta propuesta nos impiden, de momento, ir más allá.

\section{VALORACIÓN DEL CONJUNTO}

La propuesta que surge a partir de esta revisión contempla, para el caso concreto de la sala del Dosel de la cueva de la Victoria, un espacio artístico-funerario adaptado a una estancia subterránea en la que fueron dispuestos dos grandes grupos de motivos pictóricos enfrentados aprovechando la fisonomía longitudinal de la misma, constituyendo así un ámbito compositivo doble y simétrico.

Por otro lado, aunque los recursos gráficos con que se confeccionó este insólito marco expresivo no son tan inusuales: figuras humanas repetitivas complementadas con signos, todos ellos de tipologías bien conocidas y muy características, el friso A presenta una composición lo suficientemente amplia y coherente como para permitir el planteamiento de hipótesis interpretativas que otras estaciones no permiten articular. Y la nuestra es que estamos ante la representación de un grupo humano en su territorio y, lo que es más importante, probablemente el mismo que realizó las pinturas y que fue enterrado en este lugar. 
Los numerosos casos conocidos en que cabe relacionar este tipo de manifestaciones gráficas con los enterramientos en cueva, parecen abundar en la idea de unas fuertes connotaciones funerarias, muy a tener en cuenta también debido a su cada vez mejor conocida presencia en los monumentos megalíticos. Sin estar en desacuerdo, debe recordarse que las mismas tipologías se dan también sobre soportes cuyo carácter pudo no estar necesariamente vinculado con estos ritos, como pueden ser los abrigos rocosos al aire libre $u$ otros elementos de la cultura material, lo que abunda en el carácter adaptativo y polivalente que, desde hace tiempo, venimos observando respecto al arte esquemático (Maura, 2003 b; Cantalejo, Maura y Becerra, 2006).

Como también hemos defendido en otros foros, las grafías esquemáticas distan mucho de poderse o haberse podido interpretar de manera directa e inmediata, incluso conociendo sus códigos, ya que no parecen articularse a partir de una sintaxis definida. Este es un hecho que siempre limitará nuestros márgenes de comprensión. Sin embargo, tanto la insistencia en determinadas tipologías (Soria y López, 1989; Martínez, 1984) como la repetición de algunas asociaciones entre motivos, suponen un indicio claro de intencionalidad expresiva. La aplicación de atribuciones de carácter semiológico, como pueden ser la presencia o ausencia de indicación del sexo masculino, o la significación numérica que cabría atribuir a tipologías como los pectiniformes o los ramiformes, parecerían un punto de partida. A través de este tipo de líneas de investigación podrían asignarse significados concretos para cada una de las tipologías antropomorfas, atendiendo no sólo a razones de género y número, sino también de actitud (Mas y Finlayson, 2001), estado, acción, o condición. La cuestión es precisar si una misma tipología tuvo idéntico significado en todos los lugares con arte esquemático de la Península, o si se dieron variantes interpretativas en función del soporte en que fueron plasmadas.

Sea como fuere, del análisis en concreto del friso A de la cueva de la Victoria se desprendería que aquel grupo humano que en la Prehistoria habitó estas tierras pudo haber querido dejar aquí constancia de sí mismo y de su mundo, y que no lo hizo de una forma aleatoria e idealista, sino ordenada y realista, ofreciéndonos detalles referentes a su estructura social, a su concepción del territorio y a sus modos de vida y de trabajo.

Hemos dejado para el final la problemática del antropomorfo localizado en el friso $B$ cuya tonalidad oscura, ajena por completo al resto de figuraciones, y su mayor calcificación lo convierten en un elemento controvertido. No obstante, todo apunta a que se trata de un motivo anterior a los frisos, aunque, como se ha dicho, su tipología y sus medidas sí son coherentes con el conjunto, lo que le aproxima a éste a la vez que lo aleja de una posible atribución pleistocénica. Por ello, cabría proponer que esta figura pudo corresponder a los primeros momentos de utilización de la sala como recinto funerario, hecho que debió ocurrir, a juzgar por las evidencias arqueológicas anteriormente comentadas, hacia un Neolítico final. A par- 
tir de entonces, y hasta momentos avanzados del Calcolítico, como mínimo, este edificio natural habría servido de panteón a la comunidad propietaria del territorio circundante, un lugar en el que todos sus miembros, llegada la hora, tendrían derecho a ser enterrados junto a los que les precedieron, según los ritos funerarios de sus ancestros, entre los que se contaba, sin duda, la incorporación de las manifestaciones gráficas propias de la época, basadas en la esquematización de las formas y en la estandarización de muchos de estos esquemas, pero que en esta ocasión trascendieron las barreras formales para impregnar de esa índole conceptual a la misma estructura compositiva, expresada mediante recursos como la horizontalidad y la verticalidad o la agrupación de figuras, rayando al mismo tiempo hasta tal punto lo narrativo que, por una vez y aparentemente, se nos permite entrever el argumento del discurso expresivo: un grupo humano que controla y explota el territorio que le pertenece por herencia.

No deben perderse de vista en este punto la valoración de las sepulturas megalíticas en cuanto a referentes de propiedad territorial continuada por parte de un linaje, y que las estructuras morfológicas de algunas cuevas con enterramientos han sido comparadas con las de los sepulcros de corredor, cumpliendo una posible función sustitutoria del monumento megalítico (Sanchidrián, 1984-85: 245), ya que ambos fenómenos serían contemporáneos, así como la presencia en estos últimos de manifestaciones gráficas (Bueno y Balbín, 1995; 2000) y el carácter eminentemente colectivo de ambos tipos de inhumaciones.

Correcta o no, nuestra propuesta se origina desde la certeza de que las pinturas rupestres de la cueva de la Victoria podrían ofrecer algunas claves al estudio general de la iconografía esquemática. Entendemos que a partir de su análisis pormenorizado cabe extraer lecturas que en otros enclaves artísticos más sumarios (la gran mayoría) no son posibles y suponemos que futuros estudios y comparativas vendrán a matizar nuestra interpretación, corrigiendo nuestros errores u omisiones, dialéctica que esperamos sirva, en definitiva, para ampliar los límites de la comprensión de este singular fenómeno expresivo. 


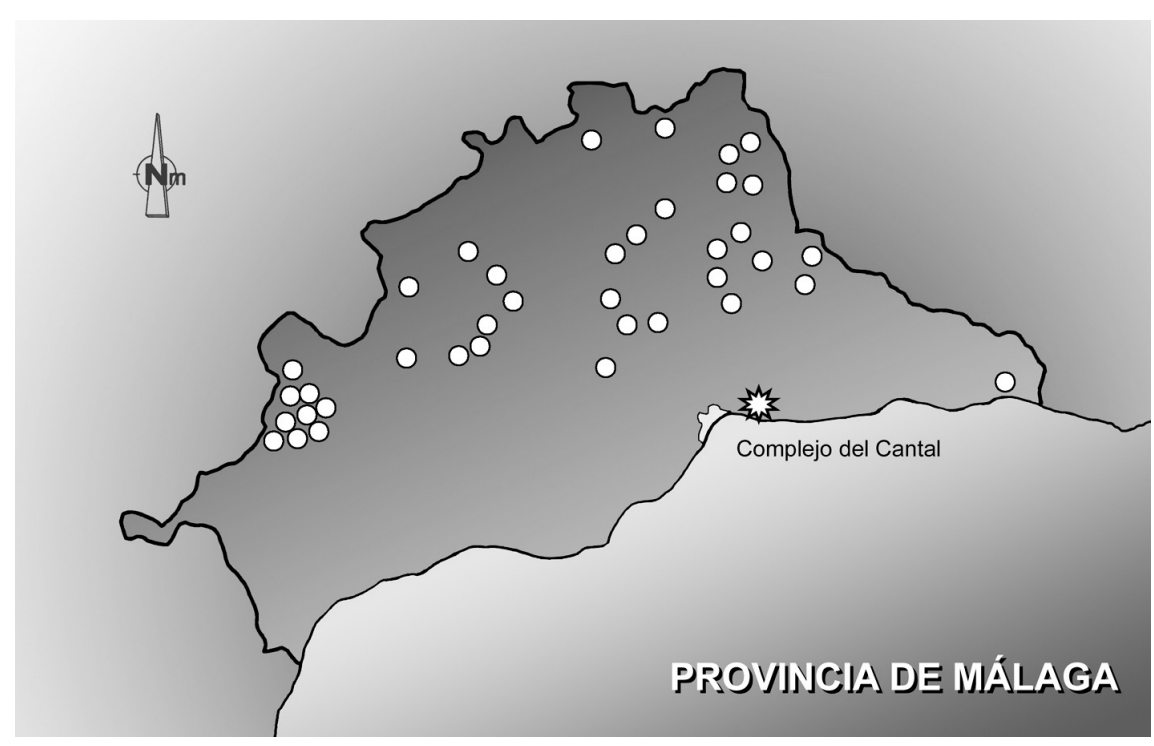

Fig. 1. Dispersión geográfica del arte esquemático en la provincia de Málaga y localización del complejo subterráneo del Cantal.

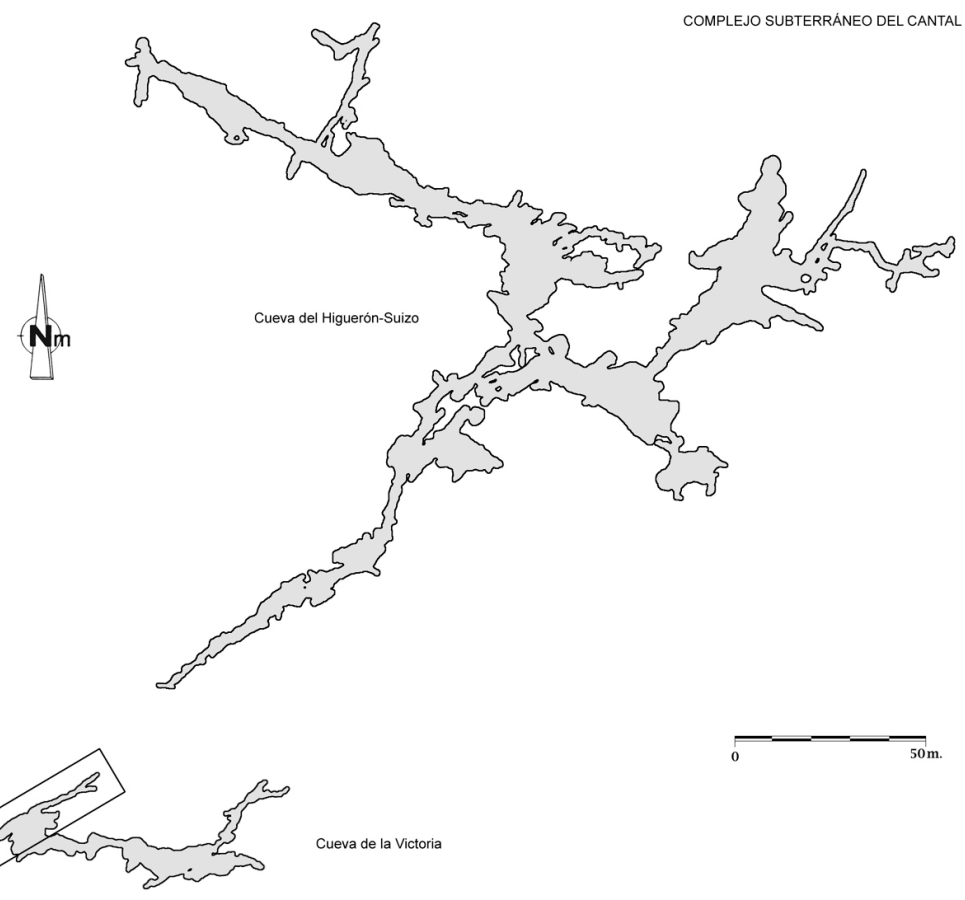

Fig. 2. Croquis topográfico del complejo del Cantal y señalización de la zona donde se encuentran las pinturas esquemáticas. 

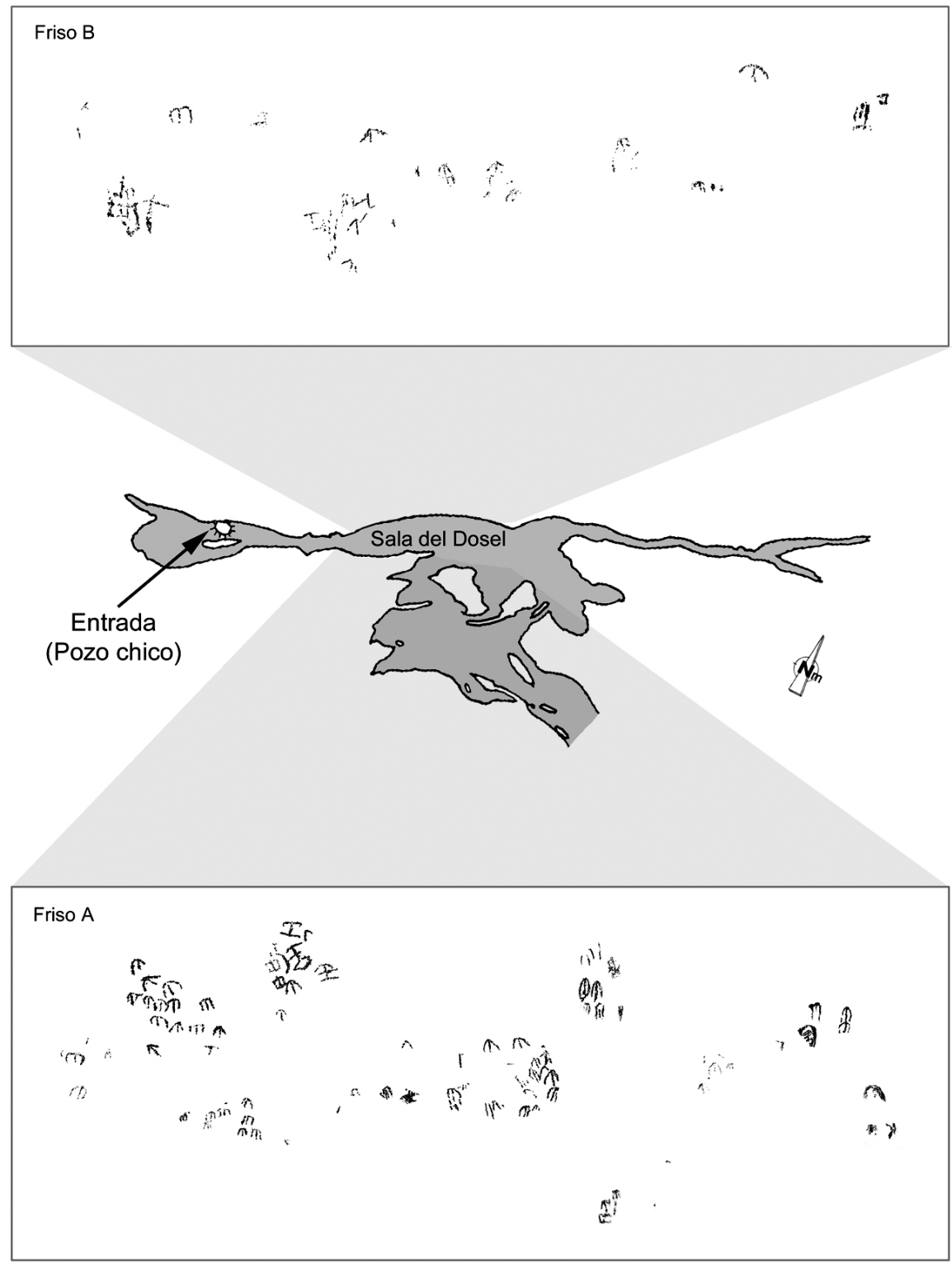

Fig. 3. Situación de los frisos en la Sala del Dosel. 

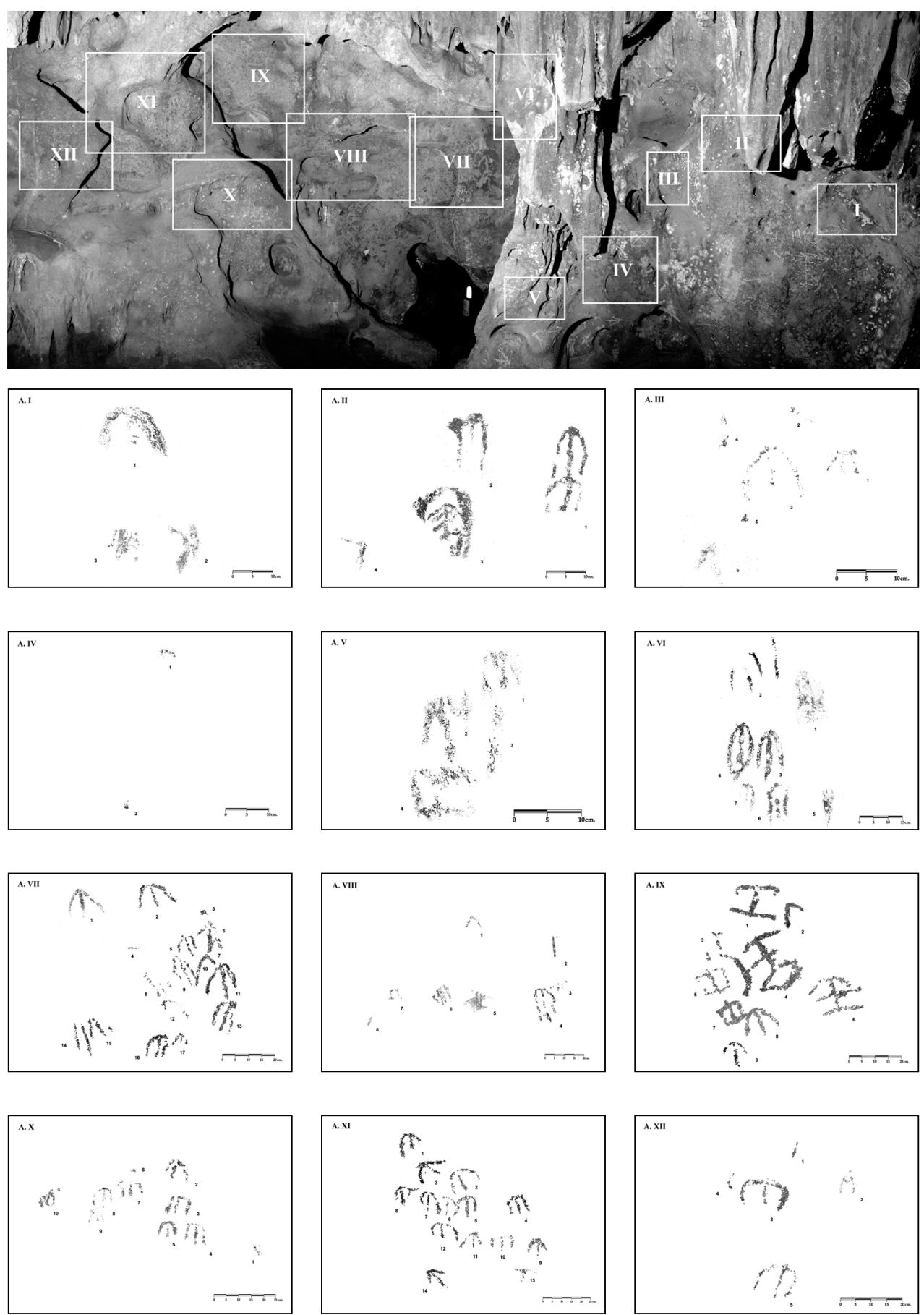

Fig. 4. Distribución de los paneles en el friso A (A.I a A.XII). 

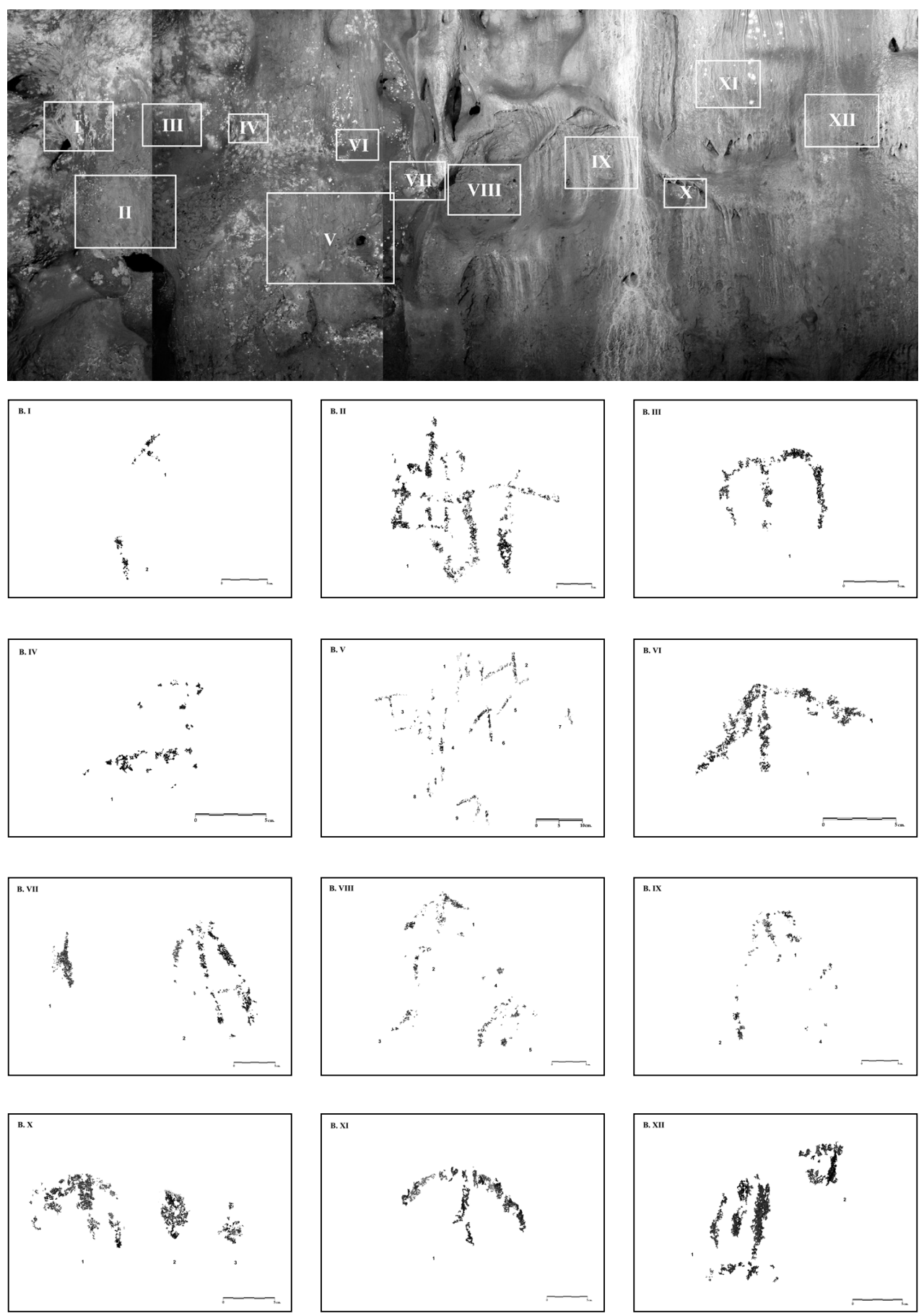

Fig. 5. Distribución de los paneles en el friso B (B.I a B.XII). 


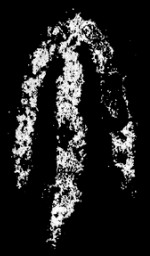

A

$\mathbf{E}$

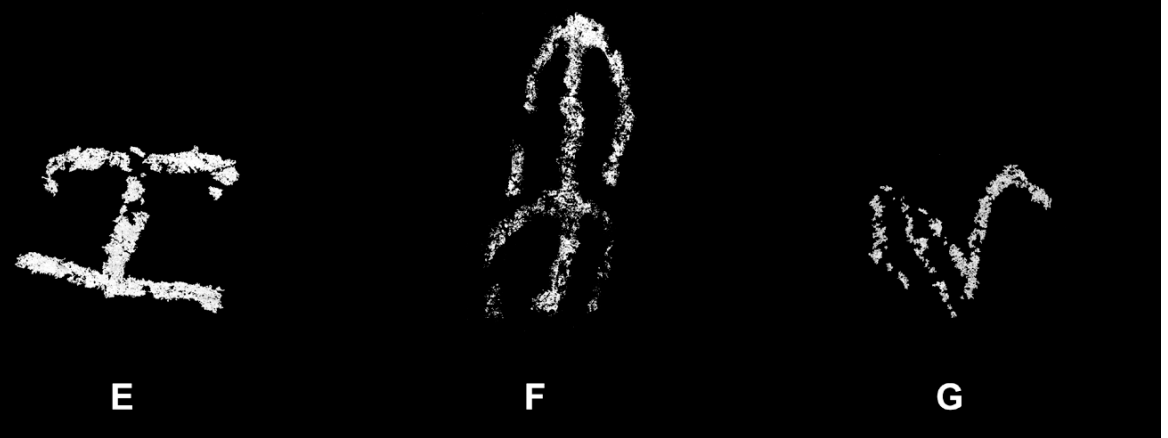

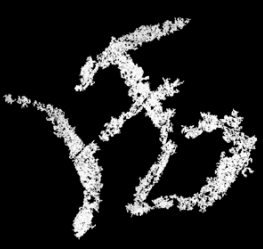

B

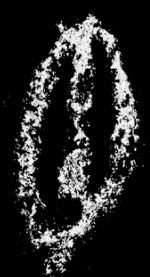

C

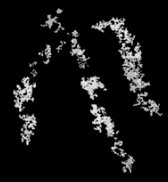

D

Fig. 6. Tipologías antropomorfas: A. Ancoriforme; B. Cruciforme con piernas en arco; $C$. «Brazos en asa»; D. "Tipo golondrina»; E. Doble «T»; F. Brazos y piernas en arco; G. Objeto asociado.

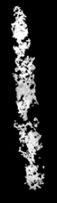

A

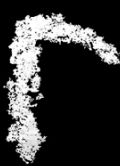

B

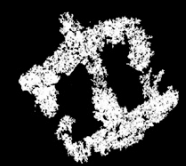

C

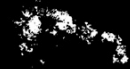

D

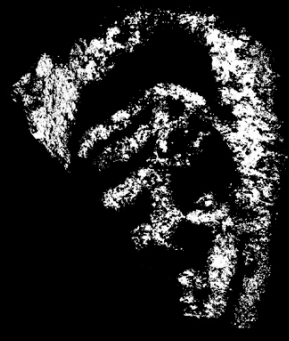

$\mathbf{E}$

Fig. 7. Tipologías de los signos: A. Barra; B. Ángulo; C. Rectangular; D. Corchete; E. Signo complejo. 


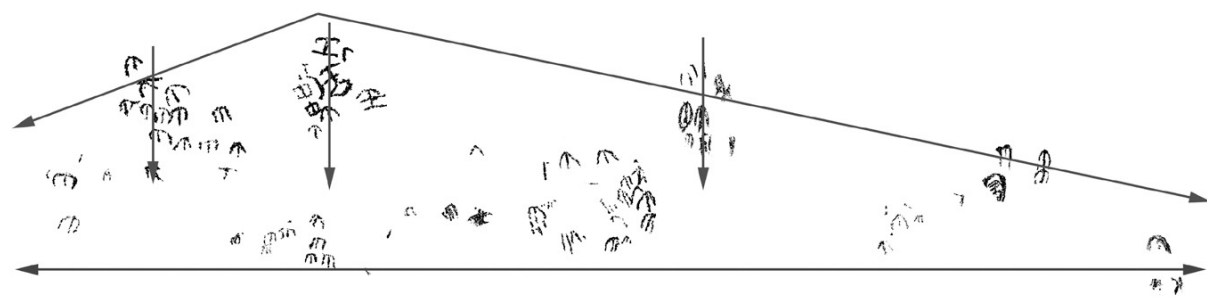

$N^{3}$

Fig. 8. Friso A: Estructura compositiva.

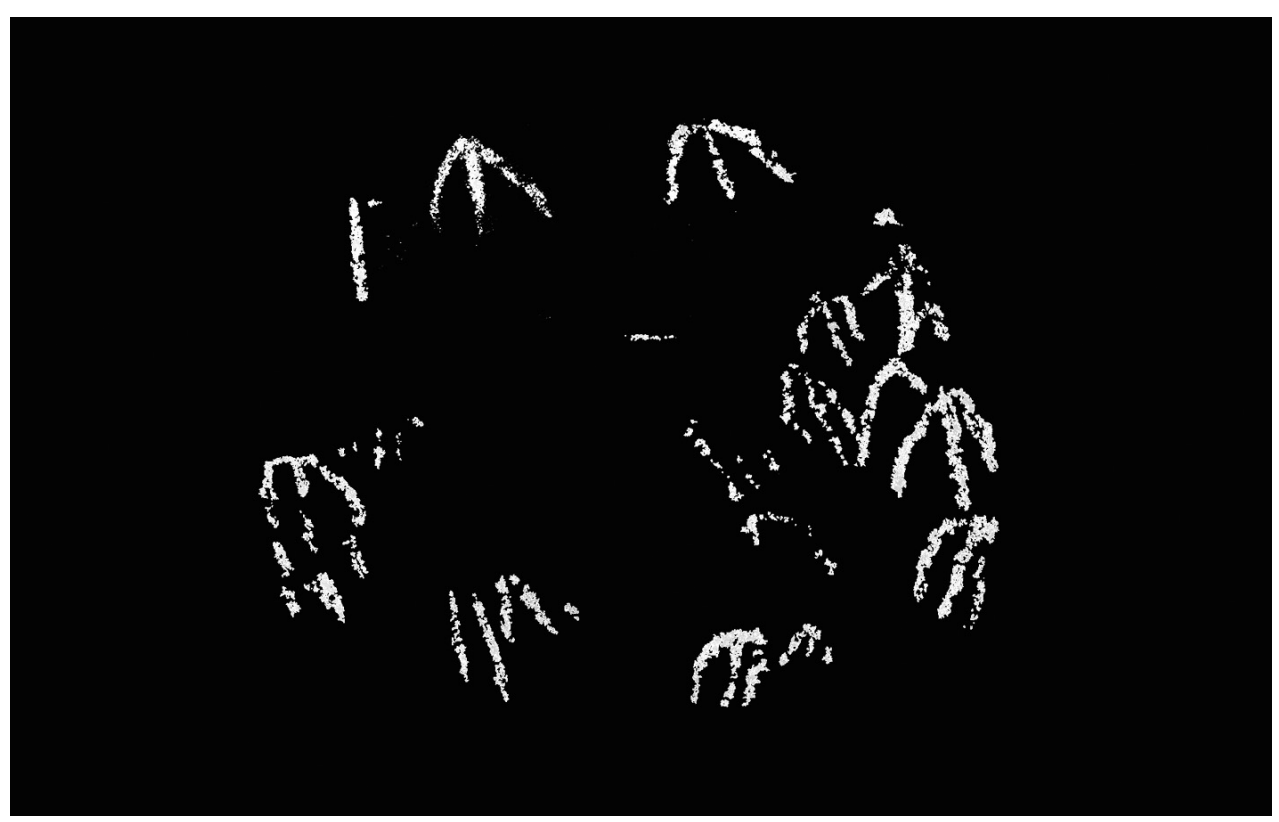

Fig. 9. Composición en círculo. 


\section{BIBLIOGRAFÍA}

Acosta Martínez, P. (1983): «Técnicas, estilo, temática y tipología en la pintura rupestre esquemática hispana», Zephyrus, XXXVI, pp. 13-25.

Almagro, M. y ARribas, A. (1963): El poblado y la necrópolis megalíticos de Los Millares (Santa Fe de Mondújar, Almería), Bibliotheca Praehistorica Hispana, III, Madrid.

BÉCARES PÉrez, J. (1983): «Hacia nuevas técnicas de trabajo en el estudio de la pintura rupestre esquemática», Zephyrus, XXXVI, pp. 137-148.

Bueno, P. y Balbín, R. (1995): «El papel del elemento antropomorfo en el arte megalítico ibérico», Revue Archéologique de l'Ouest, 8, pp. 41-64.

- (2000): «Art mégalithique et art en plein air: Approches de la définition du territoire pour les groupes producteurs de la péninsule ibérique», L'Anthropologie, 104, pp. 427-458.

Cantalejo, P., Maura, R. y Becerra, M. (2006): Arte rupestre prehistórico en la Serranía de Ronda, Editorial la Serranía, Ronda (Málaga).

-, Maura, R. Espejo, M. ${ }^{a}$ M., Ramos, J., Medianero, J., Aranda, A. y Durán, J. J. (2006): La Cueva de Ardales: Arte prehistórico y ocupación en el Paleolítico Superior, CEDMA Ediciones, Málaga.

-, Maura, R., Aranda, A. y Espejo, M. ${ }^{a}$ M. (2007): Prehistoria en las cuevas del Cantal (Rincón de la Victoria), Ayuntamiento de Rincón de la Victoria - Editorial la Serranía, Rincón de la Victoria (Málaga).

CoRtés SÁnchez, M. (2002): «El Paleolítico Superior Final en el sur de la Península Ibérica: los yacimientos de la provincia de Málaga», Mainake, XXIV, pp. 279-300.

DURÁn VALSERO, J. J. (1994): Cuevas habilitadas de la provincia de Málaga, Diputación de Málaga, Málaga.

Espejo M. a M. y CANTAlejo, P. (1996): «Arte Prehistórico en las Cuevas del Cantal, Rincón de la Victoria (Málaga)», Revista de Arqueología, 179, pp. 14-21.

—, EspinAR, I. y CANTALEJO, P. (1986): «Documentación gráfica del arte rupestre existente en el complejo subterráneo del Higuerón, Rincón de la Victoria (Málaga)», Anuario Arqueológico de Andalucía. (II) Actividades sistemáticas, pp. 216-223.

-, Cantalejo, P., Maura, R. y Ramos, J. (2007): «Arte rupestre paleolítico en el complejo de cuevas del Cantal (Victoria, Higuerón, Suizo), en el Rincón de la Victoria (Málaga)», Mainake.

ForTEA PÉREZ, F. J. (1973): Los complejos microlaminares y geométricos del Epipaleolítico Mediterráneo español, Memorias del Seminario de Prehistoria y Arqueología, 4, Salamanca.

GimÉnEZ REYNA, S. (1941): «Nota preliminar sobre la Cueva de la Victoria en la Cala», Actas y Memorias de la Sociedad Española de Antropología, Etnografía y Prehistoria, XV.

- (1946): Memoria arqueológica de Málaga hasta 1946, Málaga.

MÁRQUeZ, A. M. ${ }^{a}$ y SANCHIDRIÁN, J. L. (2005): «Esquemas entre tinieblas. Planteamientos sobre el fenómeno esquemático en la oscuridad», Actas del Congreso de Arte Rupestre en la España Mediterránea, Alicante, pp. 311-331.

- (2006): «Revisión del arte prehistórico de la Cueva de la Victoria (Rincón de la Victoria. Málaga)», Actas del Congreso Arte Rupestre Esquemático en la Península Ibérica, Comarca de los Vélez (Almería), pp. 417-420.

Martínez García, J. (1984): «El Peñón de la Virgen: Un conjunto de pinturas rupestres en Gilma (Nacimiento, Almería). Asociaciones recurrentes, simbolismo y modelo de distribución», Cuadernos de Prehistoria de la Universidad de Granada, 9, pp. 39-84.

- (1988-89): «Análisis de un sistema de parentesco en las pinturas rupestres de la Cueva de Los Letreros (Vélez Blanco, Almería)», Ars Praehistorica, 7-8 (Homenaje a Eduard Ripoll), pp. 183-193.

- (2002): «Pintura Rupestre Esquemática: El Panel, Espacio Social», Trabajos de Prehistoria, 59 (1), pp. 65-87.

- (2006): «La pintura rupestre esquemática en el proceso de transición y consolidación de las sociedades productoras», Actas del Congreso Arte Rupestre Esquemático en la Península Ibérica, Comarca de los Vélez (Almería), pp. 33-56.

MAS, M. y FINLAYSON, C. (2001): «La representación del movimiento y la actitud (antropomorfos y zoomorfos) en los motivos pictóricos de los abrigos rocosos de Sierra Momia (Benalup-Casas Viejas, Cádiz)», Espacio, Tiempo y Forma. Serie I: Prehistoria y Arqueología, 14, pp. 185-202.

Maura MiJARES, R. (2003 a): «Valoración del fenómeno esquemático en el arte prehistórico de Málaga», Actas del Il Congreso de Paleontología «Villa de Estepona»: Paleoantropología y Prehistoria Pliocénica, 3, pp. 131-138.

- (2003 b) «Arte rupestre y entorno arqueológico: las cuencas de los ríos Turón y Guadalteba (Málaga)», SPAL, 12, pp. 83-98. 
- y CANTALEjo, P. (2004): «La metodología aplicada en la cueva de Ardales para la documentación del arte prehistórico", Actas de las Jornadas Temáticas Andaluzas de Arqueología. Sociedades recolectoras y primeros productores, Ronda (Málaga), pp. 317-331.

MORALES, A. y MÁRQUEZ, J. E. (1984): «Las pinturas esquemáticas malagueñas y sus relaciones con culturas materiales», Arqueología Espacial, 3, pp. 175-195.

MuÑoz GAMBero, M. (1971-73): «Pinturas rupestres inéditas malagueñas», Malaca, 6.

NAvARRETE EnCISO, M. ${ }^{a}$ S. (1976): «La Cultura de las Cuevas con cerámica decorada en Andalucía Oriental», Cuadernos de Prehistoria de la Universidad de Granada, 2, pp. 59-73.

Pérez de BARRADAS, J. (1968): Los primeros pobladores de la Costa del Sol, Málaga, Publicaciones de la Caja de Ahorros Provincial de Málaga.

Rubio Díaz, A. (1976): «Las pinturas rupestres de la Cueva de la Victoria (La Cala, Málaga)», Zephyrus, XXVI-XXVII, pp. 233-242.

SANCHIDRIÁN TORTI, J. L. (1984-85): «Algunas bases para el estudio de los actos funerarios eneolíticos: Sima de la Curra (Carratraca, Málaga)", Zephyrus, XXVII-XXXVIII, pp. 227-248.

- y MÁRQUEZ, A. M. a (2003): «Radiodataciones y sus repercusiones en el arte prehistórico malagueño», Mainake, XXV, pp. 275-292.

SANTANA FALCón, I. (2001): «Evaluación de factores de riesgo en las estaciones con arte rupestre de la provincia de Málaga», Boletín del Instituto Andaluz del Patrimonio Histórico, 36, pp. 62-74.

SORIA, M. y LóPEZ, M. G. (1989): El arte rupestre en el Sureste de la Península lbérica, La Carolina (Jaén). 